\title{
Effect of pulsed light on shelf life of chill stored yellowfin tuna (Thunnus albacares) steaks
}

\author{
T. R. ANANTHANARAYANAN, C. T. NITHIN, TOMS C. JOSEPH, J. BINDU AND \\ T. K. SRINIVASA GOPAL \\ ICAR-Central Institute of Fisheries Technology, Matsyapuri P. O., Willingdon Island, Kochi-682 029, Kerala, India \\ e-mail: ananthu7@gmail.com
}

\begin{abstract}
In this study, the effect of pulsed light (PL) treatment on the shelf life extension of yellowfin tuna (Thunnus albacares) steaks was investigated. Tuna steaks of $1 \mathrm{~cm}$ thickness weighing $80 \mathrm{~g}$ packed in 300 gauge cast polypropylene pouches were subjected to PL treatment using Xenon pulse light machine RC-847. The samples were stored at $2 \pm 1^{\circ} \mathrm{C}$ and analysed at specific time intervals. Shelf life studies were carried out in terms of reduction of aerobic flora as inferred from the total plate count (TPC) and the psychrophilic count. The samples were also evaluated in terms of colour $\left(\mathrm{L}^{*}, \mathrm{a}^{*}\right.$ and $\left.\mathrm{b}^{*}\right)$, biochemical and sensory parameters. The initial reduction as well as lower rate of increase in the microbial count on the PL treated samples clearly highlighted the efficiency of PL technology as a novel non-thermal preservation technique. Low values of chemical indicators of spoilage and better values of sensory and colour values of PL treated samples also suggested the efficacy of PL treatment in microbial inactivation. An overall extension of 13 days of shelf life was achieved for PL treated samples whereas control samples were rejected on $13^{\text {th }}$ day.
\end{abstract}

Keywords: Microbial reduction, Pulsed light, Shelf life, Yellowfin tuna

\section{Introduction}

Tunas are highly migratory fish having a universal distribution in temperate as well as tropical oceans and are one of the highest traded among all the commercially available fishes in the world market. Yellowfin tuna (Thunnus albacares) is a species of high commercial importance worldwide, particularly in the raw sashimi market of Japan. Hence, decontamination of raw tuna meat for the extension of its shelf life finds commercial importance in the seafood industry. Seafood is one of the highly perishable groups among all the muscle foods, as they are extremely prone to rapid textural changes and quality deterioration (Ashie et al., 1996). The initial loss of freshness is caused by enzymatic and chemical reactions whereas microbial activity predominates during the latter part of storage period (Gram, 1995; Gram and Huss, 1996).

Thermal methods are one of the most common conventional food processing techniques prevalent in the current food processing industrial setup. However, the heating effects of these techniques generally cause deterioration in terms of nutrition and sensory quality which has led to a shift of research interest in the recent years towards non-thermal processing methods (Palmieri and Cacace, 2005; Bang-Yuan et al., 2015). Among the novel non-thermal techniques, pulsed light technology
(Muredzi, 2012; Vanderroost et al., 2014) is found to be advantageous, as decontamination is achieved mainly by the action of UV rays on microorganisms (Tatiana et al., 2009; Fernandez and Hierro, 2016). This is a very fast technique with very small heating effects and negligible reduction in sensory attributes of the food matrices, while being eco-friendly and cost effective (Butz and Tauscher, 2002; Leistner, 2002; Palmieri and Cacace, 2005; Sofos, 2005; Oms-Oliu et al., 2010; Ortega-Rivas, 2012). Food and Drugs Administration (FDA) of the United States has approved its use for decontamination of food and food surfaces (FDA, 1996). This technology can be used for decontamination of equipments and food packaging materials as well (Dunn et al., 1995).

PL equipment works with Xenon flash lamps that can emit several short pulses of high intensity broad spectrum light ranging from UV to near infrared. The intensity of the light produced is 20000 times that of sunlight received at the surface of the earth (Dunn et al., 1995; MacGregor et al., 1998). Light pulses are produced by power amplification methods, wherein the electrical energy is stored in a capacitor for small fractions of a second, which is then released by efficient pulse compression techniques, within much shorter time duration of the order of microseconds. This provides amplification of power with a minimum amount of additional energy consumption (Go'mez-Lo' pez et al., 2007). This current energises the 
Xenon gas inside the chamber of the lamp unit, to produce short intense bursts of light.

In PL technology, the inactivation of microorganisms is mainly achieved by the photochemical action of the UV-C part of the light spectrum with a wavelength range of 200-280 nm (Rowan et al., 1999; Wekhof, 2000; Wang et al., 2005; Go'mez-Lo'pez et al., 2007). The absorption peak of microbial DNA is in the UV range and thus exposure to PL strongly induces lethal chemical changes to its structure, wherein the pyramidine bases are transformed to pyramidine dimers and degradation of its cell wall. Such changes in the DNA chain imparts irreversible damage preventing further replication and ultimately leads to cell death (McDonald et al., 2000; Gomez-Lopez et al., 2007). Experiments on enzymatic repair of DNA post-exposure to pulse light treatment, have shown that the extent of damage is severe enough to prevent DNA repair (PPT, 1999). The high energy content of short intense pulses amplifies the destruction mechanisms of individual wavelength contents. A few studies have also been reported on the photo thermal action of PL (Takeshita et al., 2003; Turtoi and Nicolau, 2007), though the effect depends on factors like the fluence of the irradiated light and absorption properties of the food matrices (Pataro et al., 2011).

Multitudinous studies have been conducted on the effect of PL on various food matrices in the past decade (Fernandez and Hierro, 2016). However, only very few studies have been reported on its effect on fish and fishery products as compared to meat products (Fernandez and Hierro, 2016). Even among the very few studies conducted on the effect of PL on microbial inactivation on fish samples, most of the studies were carried out on samples inoculated by specific microbes. Very few studies have been conducted till date on the natural microflora of fish samples (Fernandez and Hierro, 2016). The present study was carried out to evaluate the effect of PL treatment on the quality and shelf life extension of yellowfin tuna steaks stored at chilled condition, in terms of biochemical changes, colour changes and sensory evaluation scores.

\section{Materials and methods}

\section{Sample collection and preparation}

Yellowfin tuna having a mean weight of $3 \mathrm{~kg}$ were purchased from local fish market and brought to the laboratory in iced condition. These fish samples were cleaned, gutted and washed in potable water. Steaks weighing $80 \mathrm{~g}$ each were prepared from the fish muscle after removal of red meat and bones, from which steaks with uniform thickness of $1 \mathrm{~cm}$ were carefully selected for the experimental analysis. The steaks were packed in 300 gauge cast polypropylene pouches of size 14 x $18 \mathrm{~cm}$ to hold these $1 \mathrm{~cm}$ thick steaks. The pouches were further divided into 2 batches of 25 each, one for control and one for PL treatment. All pouches were placed in flake ice in the ratio 1:2 (fish: ice) and were stored in a chill room maintained at $2 \pm 1^{\circ} \mathrm{C}$ for further analysis.

\section{Pulsed light treatment}

The samples were subjected to pulsed light treatment using XENON Steripulse XL 3000 RC847. This model consists of 16 " Xenon gas lamps and a quartz table inside a polished stainless steel treatment chamber enclosed in a metal housing. The lamp is capable of producing flashes of broad spectrum white light in the range of 100-1100 nm. Fifty-four percent of the total energy of the broad spectrum light falls in the UV range (Krishnamurthy et al., 2010). The lamp generates 3 pulses per second and delivers $1.27 \mathrm{~J} \mathrm{~cm}^{-2}$ per pulse for an input voltage of $3800 \mathrm{~V}$ at the quartz table as per the manufacturer's specification. Each pouch was individually exposed to PL for $6 \mathrm{sec}$. The time of exposure was estimated to be a value of $6 \mathrm{sec}$ from the photodiode readings and the manufacturer's directions so as to fix the fluences level within $12 \mathrm{~J} \mathrm{~cm}^{-2}$ to confirm with the FDA regulations (FDA, 1996).

\section{Sampling procedures, reagents and media}

Sampling was carried out at periodic intervals by drawing two pouches at random from each of the control and PL treated sample batch, one for microbiological and the other pouch for chemical and sensory evaluation. Sampling was done in triplicate groups for statistical studies of the mean values. Chemicals used for the experiments were of Fisher Scientific Brand, AnalaR-grade or guaranteed reagent grade. Dehydrated bacteriological media used for analysis was plate count agar (PCA, DIFCO).

\section{Microbiological analysis}

\section{Total plate count}

From each of the sample groups, $10 \mathrm{~g}$ portion of the steak was weighed and transferred to a stomacher bag to which $90 \mathrm{ml}$ of sterile normal saline $(0.85 \%)$ was added and homogenised for $60 \mathrm{~s}$ at $230 \mathrm{rpm}$ using a lab stomacher (Seward Stomacher Model No. 400, England). Homogenised sample was diluted tenfold with normal saline $(0.85 \%)$ for microbiological analysis. These homogenates were spread on the surface of plate count agar (DIFCO). The inoculated plates were incubated at $35 \pm 2^{\circ} \mathrm{C}$ for $48 \mathrm{~h}$. Total plate counts (TPC) were determined by spread plate method (AOAC, 2002).

\section{Psychrophilic count}

The tenfold diluted homogenised samples were spread on the surface of plate count agar (DIFCO) and incubated at $7^{\circ} \mathrm{C}$ for 10 days for determining the psychrophilic bacterial counts (APHA, 2015). 


\section{Biochemical analysis}

Chemical analysis was carried out on the fish muscle which was ground using mortar and pestle. Total volatile base nitrogen (TVB-N) was estimated by the microdiffusion method (Conway, 1950). TVB-N was expressed in $\mathrm{mg} 100 \mathrm{~g}^{-1}$ of the sample. Free fatty acid (FFA) values and peroxide values (PV) were estimated as per AOAC (2002) and expressed as $\mathrm{mg}$ oleic acid $100 \mathrm{~g}^{-1}$ of fish sample and miliequivalents of $\mathrm{O}_{2} \mathrm{~kg}^{-1}$ of fat respectively. Thiobarbituric acid (TBA) value of the fish samples was estimated spectrophotometrically (Tarladgis et al., 1960) to assess the oxidative stability of the fish samples and expressed in mg malonaldehyde $\mathrm{kg}^{-1}$ of fish sample.

\section{Colour measurement}

Colour of the samples was measured using the Hunter Lab Colourimeter Model No D/8-S (Miniscan XE Plus) with geometry of diffuse $/ 8^{\circ}$ (sphere $8 \mathrm{~mm}$ view) and an illuminant of $\mathrm{D} 65 / 10^{\circ}$ (Shah, 1991). The $\mathrm{L}^{*}, \mathrm{a}^{*}$ and $\mathrm{b}^{*}$ value or CIE Lab colour space is an international standard for colour measurement adopted by the Commission Internationale d' Eclairage (CIE) in 1976.

\section{Sensory evaluation}

Sensory analyses of the samples were carried out by 12 panelists, based on the 9-point hedonic scale (Meilgaard et al., 1999). Sensory acceptability of the control and PL treated samples were conducted on samples cooked for $10 \mathrm{~min}$ in $2 \%$ salt solution. Panelists were provided with a sensory evaluation sheet containing all the sensory attributes to evaluate the overall acceptability of the sample. A value of 4 was considered as the border line of acceptability. Average overall acceptability value of the 12 panelists for each sample was calculated for control and PL treated samples.

\section{Statistical analysis}

Experiments were conducted in triplicate and the mean values were statistically analysed using SPSS 11.0. One way ANOVA was conducted to assess the significance of differences in the mean values of each of the tests with a significance level of 0.05 .

\section{Results and discussion}

\section{Changes in TVBN}

The changes in TVBN values of PL treated and control samples, with respect to the storage days are shown in Fig.1. During the initial days, though the TVBN values of the control and the PL treated samples were very low, values of control samples were higher than that of PL samples $(p<0.05)$. This indicates the efficiency of $\mathrm{PL}$ in achieving control over the microbial action on the fish muscle. The increase in TVBN values with respect to storage days was observed to be statistically significant $(p<0.05)$ for both the samples. During the initial storage days, the increase was very slow, whereas after the $12^{\text {th }}$ day, a sharp increase in the values was observed for the control sample which persisted till the end of the storage period. In the case of PL treated samples, the rate of increase was much smaller compared to that of control. The differences widened extremely towards the end of the storage period due to the considerably slow rate of increase of TVBN in the PL samples. Throughout the storage days, the TVBN values of PL group was considerably lower than control samples and the differences were statistically significant $(\mathrm{p}<0.05)$.

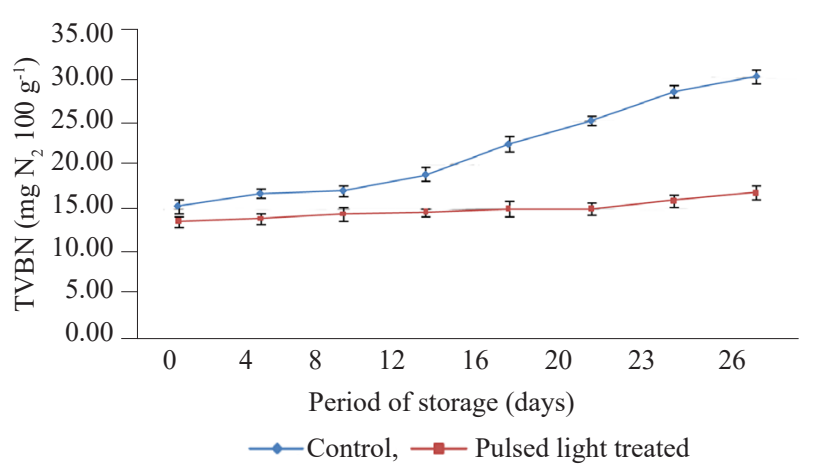

Fig. 1. Changes in TVBN content of control and PL treated yellowfin tuna steaks stored in chilled condition $\left(2 \pm 1^{\circ} \mathrm{C}\right)$.

TVBN represents the total amount of various nitrogenous compounds, released by the decomposition of the stored fish due to microbial action (Dalgaard, 2000). The TVBN of fresh fish has been reported to be in the range of 5-20 mg N $100 \mathrm{~g}^{-1}$ (Muhammet and Sevim, 2007) and a value of $25-35 \mathrm{mg} \mathrm{N}_{2} 100 \mathrm{~g}^{-1}$ has been proposed as the rejection criterion for commercial fresh fish. According to these criteria, the control sample of the present study reached the rejection limit of $25 \mathrm{mg} \mathrm{N} 2100 \mathrm{~g}^{-1}$ on the $20^{\text {th }}$ day of storage. On the same day it was only $16.89 \mathrm{mg} \mathrm{N}_{2} 100 \mathrm{~g}^{-1}$ for the PL treated sample, which is comparatively very low and falls well within the accepted criteria (Dalgaard et al., 2000; Amegovu et al., 2012). The TVBN values are reported to be highly dependent on the bacterial activity (Yusuf et al., 2010; Amegovu et al., 2012) and in general the sudden increase of TVBN values in fish muscle is considered to be due to putrefaction (Huss, 1995). The escalation in TVBN values with respect to storage days indicate the enhanced degradation of fish muscle caused by the action of more and more microbes produced by replication. No such escalation was observed in the TVBN values of PL treated samples, which indicated that the muscle degradation due to microbial action was controlled considerably. 
Autolytic microbial spoilage due to breakdown of trimethylamine oxide into trimethyl amine (TMA), dimethyl amine (DMA), ammonia, formaldehyde and other volatile amines are reported to be much stronger than autolytic enzymatic action (Huss, 1994). Low levels of TVBN values can indicate either reduced bacterial population or reduced efficiency of the bacteria in carrying out oxidative deamination of nitrogenous and/or nonnitrogenous compounds (Banks et al., 1980). The lower TVBN observed in PL samples reaffirms the efficiency of PL technology in damaging microbial DNA thereby arresting further multiplication thus achieving control over increase in microbial counts and associated spoilage of fish muscle.

\section{Changes in FFA, PV and TBA}

The changes in FFA, PV and TBA values of the PL treated and control samples are shown in Fig. 2a-c. The FFA values of both control and PL showed increasing trend with the storage period (Fig. 2a) which was found to be statistically significant $(\mathrm{p}<0.05)$ in both the cases. The FFA values increased slowly until the $8^{\text {th }}$ day in both the cases and thereafter increased rapidly till the $16^{\text {th }}$ day followed by a steady increase till the end of the storage period. The FFA values and its rate of increase for the PL

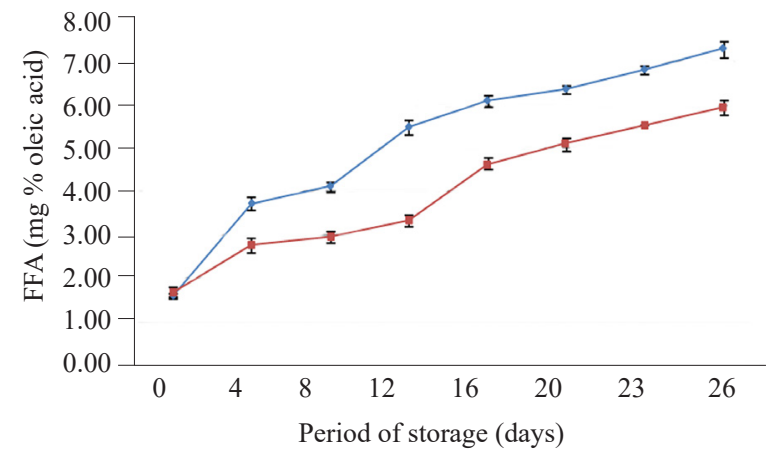

(a) treated samples were significantly lower $(\mathrm{p}<0.05)$ than that of the control sample, throughout the storage period with values ranging between 1.69 to $5.7 \%$ oleic acid $100 \mathrm{~g}^{-1}$. A similar increasing trend of FFA has been observed in chilled and iced stored sutchi catfish steaks (Viji et al., 2014) and rainbow trout steaks (Haghparast et al., 2010), both treated with sodium acetate.

FFA formation during storage is generally caused due to the hydrolysis of fat in the fish muscles which will further lead to secondary lipid reactions causing considerable quality deterioration. FFA formation by itself does not cause any loss in the nutritional quality of fish muscle. However, FFA and its oxidative products will interact with protein in the fish muscle thus deteriorating quality indices, leading to reduction of acceptability. Lipid deterioration is found to affect the shelf life of seafoods especially oily fish (McDonald and Hultin, 1987; Cho et al., 1989). The FFA further undergoes oxidation producing low molecular weight compounds releasing rancid off flavours. Therefore, the low FFA values of PL treated samples and its slower rate of increase throughout the storage period indicates the effectiveness of PL treatment in preserving freshness of the fish samples.

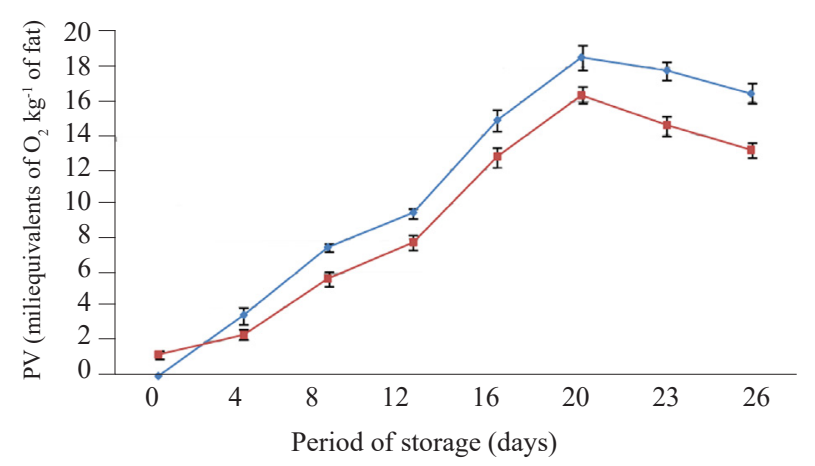

(b)

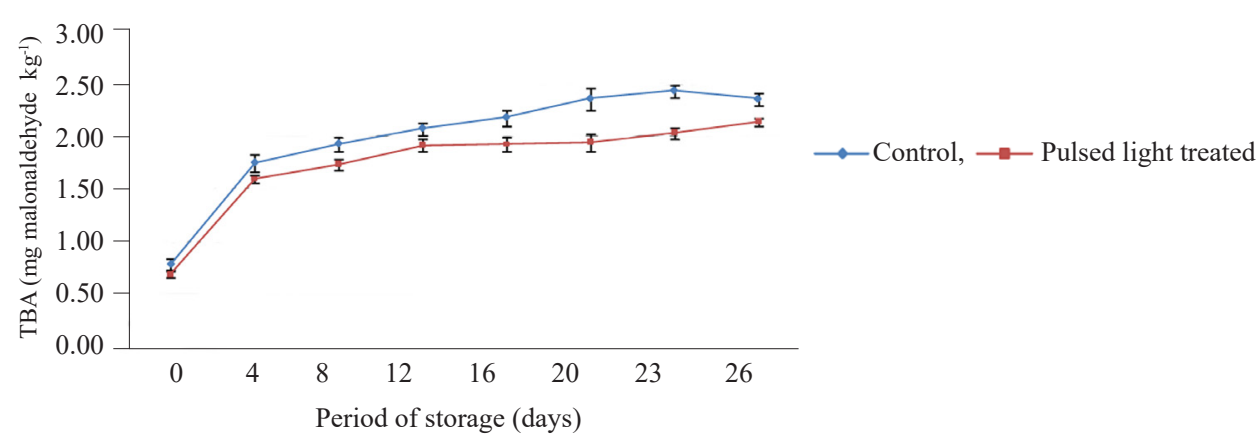

(c)

Fig. 2. Changes in lipid degradation indices of control and PL treated yellowfin tuna steaks stored in chilled condition $\left(2 \pm 1^{\circ} \mathrm{C}\right)$; (a) Free fatty acid value, (b) Peroxide value and (c) Thiobarbituric acid value 
Fig. $2 \mathrm{~b}$ shows changes in the PV for the control and PL treated samples with respect to storage period. PV which is an indicator of primary lipid oxidation, showed zero value for the control sample whereas a slightly higher value of 1.34 was observed for the PL sample on day 0 . These results are in concurrence with that of earlier studies on fresh yellowfin tuna samples (Rodriguez-Turienzo et al., 2013; Biji et al., 2016). The photo oxidative effect of PL can be a plausible reason for this slightly higher value of PV on day 0 of storage. The pattern of evolution of PV values were similar in control and PL samples, however, the rate of increase was much slower in the case of PL treated samples. Though UV light has an oxidative effect on lipids, it is also well documented that these rays applied in pulsed form for short duration will limit the reaction times through the short half-life of $\pi$ (pi) bonds (Fine and Gervais, 2004). This could explain the short duration of the observed higher PV of PL compared to control sample during the initial storage period. With further increase in the storage period, a reduction in the peroxide concentration was observed from the $20^{\text {th }}$ day to the $26^{\text {th }}$ day. It is noteworthy that throughout the study period, the PV never crossed the acceptability limit of $20 \mathrm{meqO}_{2} \mathrm{~kg}^{-1}$ fat (Lakshmanan, 2000) for both samples.

Between the $8^{\text {th }}$ and $26^{\text {th }}$ day, the difference in PV of the control and PL samples were statistically significant $(p<0.05)$ on all the days. Similar pattern of initial increase and further decrease of lipid deterioration was observed in sutchi catfish steaks under chilled and iced storage and skipjack tuna under iced storage (Mazorra et al., 2000). Such a pattern of an initial peak followed by a drop is considered to be the result of secondary oxidation of the hydroperoxides formed by the primary lipid oxidation. The initial higher levels of PV indicate the initial formation of primary oxidation products. The reduction in PV in the later phase of storage can be caused by decomposition of primary oxidation products (Boselli et al., 2005; Ozogul et al., 2006).

The changes in TBA values with respect to storage period for the control and PL groups are shown in Fig. 2c. TBA value which is an index of secondary lipid oxidation, showed an increasing trend during the storage period. TBA values are generally accepted indicators of organoleptic properties of meat (Salih et al., 1987) and a value of $2 \mathrm{mg}$ malonaldehyde $\mathrm{kg}^{-1}$ of fish is usually considered as the maximum value of acceptability (Lakshmanan, 2000). On day 0 of storage, the values differed significantly $(p<0.05)$ between the two sample groups but the values were very low which was found to increase steadily with the storage days. On the $12^{\text {th }}$ day of storage, the control group crossed the acceptability limit with a value of $2.1 \pm 0.06 \mathrm{mg}$ malonaldehyde $\mathrm{kg}^{-1}$ whereas the PL group had lower value of $1.8 \pm 0.07 \mathrm{mg}$ malonaldehyde $\mathrm{kg}^{-1}$ on the same day. Both the samples showed an increasing trend with respect to increase in storage days, which was also found to be statistically significant $(p<0.05)$ for both the groups. The differences in TBA values between the groups also showed statistical significance $(\mathrm{p}<0.05)$ throughout the storage days. It is noteworthy that the PL sample group crossed the limit only on the $23^{\text {rd }}$ day reaching a value of $2.02 \pm 0.05 \mathrm{mg}$ malonaldehyde $\mathrm{kg}^{-1}$. The increasing trend of TBA values has been generally observed in various storage studies and TBA is considered as an efficient indicator of oxidative rancidity (Nolan et al., 1989; Huang et al., 1994; Manju et al., 2007).

\section{Changes in microbial counts}

To study the effect of PL on the microbial load, the total plate count and psycrophilic counts were calculated for all the treated samples and the changes are shown in Fig. $3 \mathrm{a}$ and $\mathrm{b}$ respectively. On day 0 , the TPC for the control sample was as high as $4.7 \pm 0.03 \mathrm{log} \mathrm{cfu} \mathrm{g}^{-1}$ whereas it was $4.3 \pm 0.02 \log \mathrm{cfu} \mathrm{g}^{-1}$ for PL treated sample (Fig. 3a). It was observed that there was a significant reduction $(p<0.05)$ in microbial load for PL treated sample with respect to the control sample throughout the storage period. Statistical analysis showed that the TPC increased significantly $(\mathrm{p}<0.05)$ with respect to the period of storage for both the samples. However, the TPC of control samples exhibited a fast growth with respect to storage period. The control sample crossed the maximum acceptable limit of $5.7 \log \mathrm{cfu} \mathrm{g}^{-1}(\mathrm{ICMSF}, 1986)$ on the $13^{\text {th }}$ day, whereas the PL sample remained well within the limit until the $26^{\text {th }}$ day. Though the TPC of PL samples also showed an increasing trend, the growth was relatively slower and the TPC values were significantly lower $(\mathrm{p}<0.05)$ compared to control on all days of storage.

Several studies have reported the efficiency of pulsed light in the reduction of microbial load in various complex food matrices (Fernandez and Hierro, 2006). However, very few studies have been reported on the effect of pulsed light on microbial load reduction and shelf life extension of chilled fish samples. Among these studies, relatively more investigations have been conducted on pathogen inoculated fish samples and only very few studies have been reported on the effect of PL treatment in inactivation of natural microbiota. Among the inoculation studies, Cheigh et al. (2013) observed a reduction of 1.7, 1.9 and $2.2 \log _{\text {cfu g }}{ }^{-1}$ of Listeria monocytogenes in flatfish, salmon and shrimp fillets with treatment of $6.3 \mathrm{~J} \mathrm{~cm}^{-2}$. Similarly, Ozer and Demirci (2006) reported a load of $1 \mathrm{log} \mathrm{cfu} \mathrm{ml}^{-1}$ of E. coli $\mathrm{O} 157: \mathrm{H} 7$ and L. monocytogens on skin and muscle of raw salmon fillets and a $1 \log \mathrm{cfu} \mathrm{g}^{-1}$ reduction of L. monocytogens and Vibrio parahaemolyticus was obtained for PL treatment with $8.4 \mathrm{~J} \mathrm{~cm}^{-2}$ 
(Hierro et al., 2012). In the case of inactivation of natural microbiota, Nicorescu et al. (2014) observed that only a reduction of $0.8 \mathrm{log} \mathrm{cfu} \mathrm{g}^{-1}$ could be achieved even at a fluence of $30 \mathrm{~J} \mathrm{~cm}^{-2}$ on raw salmon and a reduction between 1 and $3.4 \log \mathrm{cfu} \mathrm{g}^{-1}$ for fluences of 10 and $30 \mathrm{~J}$ $\mathrm{cm}^{-2}$ for pork samples. An extension of lag phase in catfish fillets, with lower value of total plate count of 1.5-2 log cfu $\mathrm{g}^{-1}$ with $120-180 \mathrm{~mW} \mathrm{~cm}^{-2}$ at $253.7 \mathrm{~nm}$, was observed for the PL treated samples as compared to the untreated samples on the $9^{\text {th }}$ day (Figueroa-Garcia et al., 2002). The observation from all these studies can be consolidated as that, the inactivation of aerobic flora that could be achieved with particular PL fluencies are generally lower in the case of fish samples when compared to other food matrices. Better pathogen inactivation is generally achieved with higher fluence for most of the food matrices.

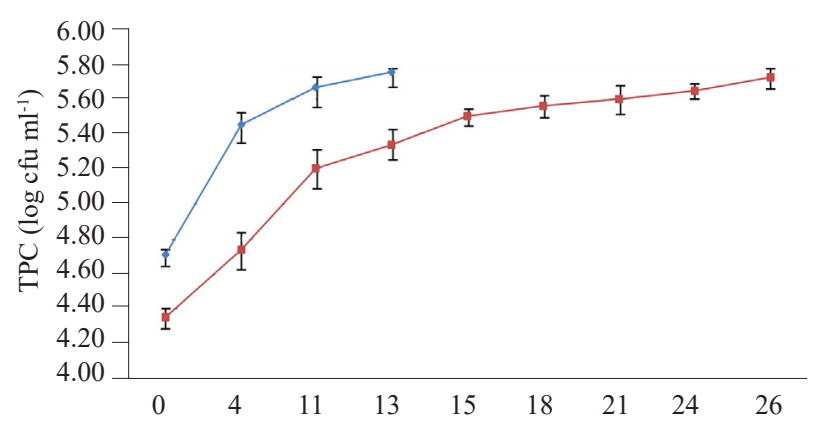

(a)

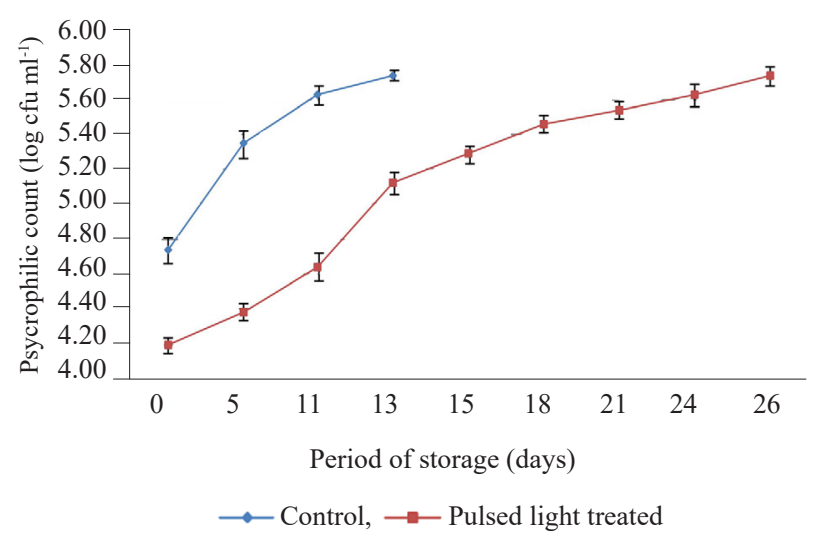

(b)

Fig. 3. Microbiological changes in control and PL treated yellowfin tuna steaks stored in chilled condition $\left(2+1^{\circ} \mathrm{C}\right)$; (a) Total plate count, (b) Psychrophilic count

From the results of our investigations, it can be inferred that the lower fluences applied here for concurring with the approved limits of FDA standards could achieve only a relatively low microbial reduction of $0.3 \log \mathrm{cfu}^{-1}$ on day 0 . In addition, relatively small increase was observed in the microbial count of PL samples within each sampling interval when compared to control. This supports the efficiency of PL treatment and its major mode of photochemical action on arresting further growth of bacterial population.

The sterilisation effect of PL depends on various factors like the absorption properties of the food substrate, type of microorganisms, spectral distribution and fluence (Ramos et al., 2012) and its inactivation effect on solid substrates is more complex compared to that of liquids (Izquier and Gomez, 2014). In the case of solid food matrices, PL inactivation becomes more difficult due to chances of light not getting into contact with the organism is more due to shadow effect caused by surface irregularities and other factors like internalisation and biofilm formation (Izquier and Gomez, 2014). However, the slower growth rate of microbial population is an extremely advantageous and sought after feature for any food processing technique and our experiments with PL treatment achieved an extension of shelf life upto 13 days in the case of yellowfin tuna steaks in chill storage condition.

Fig. $3 b$ shows the psychrophilic count of control and PL treated sample groups. There was a general trend of increase in the psychrophilic count for both the samples and the differences were significant for both the groups $(p<0.05)$ throughout the storage period. In this case also PL group crossed the acceptable limit of $5.7 \pm 0.03 \mathrm{log}$ cfu $\mathrm{g}^{-1}$ only on the $26^{\text {th }}$ day, whereas the control group crossed the limit on the $13^{\text {th }}$ day. Significant difference between the counts of the two sample groups was observed on most of the days throughout the study period $(p<0.05)$. The increase in the counts of PL samples for each sampling interval is found to be very small when compared to that of control sample throughout the storage period. This indicates that PL treatment is efficient in arresting the multiplication of microbes. From the above observations, it can be inferred that pulsed light treatment can effectively provide extension of shelf life up to 13 days on yellowfin tuna steaks.

\section{Changes in instrumental colour scores}

Fig. 4. shows the variations in $L^{*}, a^{*}$ and $b^{*}$ values of the control and PL treated samples. Though there was fluctuations in the values, a general increasing trend was observed in the Hunter's L* values indicating lightening, for both the samples with respect to increase in the storage period. However, statistical significance was not observed $(p>0.05)$ in either of the cases. Similarly, no significant differences $(p>0.05)$ were observed in the comparison of lightness between the sample groups. 
The redness of the samples represented by the $a^{*}$ values showed a steadily decreasing pattern over the storage period for both the samples. In the case of PL treated sample group, the $\mathrm{a}^{*}$ value remained high throughout the whole storage period. The browning which is mostly caused by oxidative conversions of the myoglobins in the fish samples was found to be very low in the case of PL treated sample group.

The $b^{*}$ value (yellowness) of both the samples generally showed a slight decrease during the storage period which is considerably less compared to that of $\mathrm{a}^{*}$. The $b^{*}$ values of the two sample groups did not differ significantly $(p>0.05)$ with respect to storage period. Even the differences between the $b^{*}$ values of the two groups were not found to be statistically significant $(p>0.05)$ on any of the storage days.

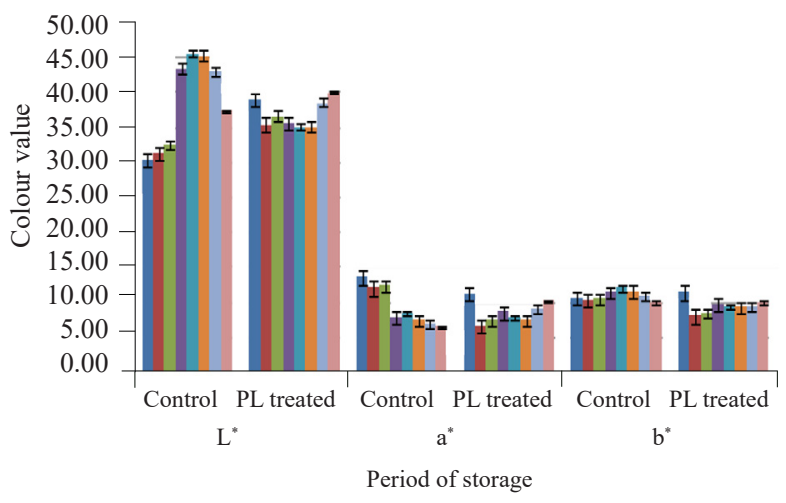

$\square 0, \square 4, \square 8, \square 12, \square 16, \square 20, \square 23, \square 26$ (days)

Fig. 4. Changes in $L^{*}, a^{*}$ and $b^{*}$ colour values of control and PL treated yellowfin tuna steaks stored in chilled condition $\left(2 \pm 1^{\circ} \mathrm{C}\right)$ with respect to storage days

The overall observations indicate that lightness and yellowness are not altered considerably throughout the storage period and that the redness is almost preserved until the last day of storage period. Generally, acceleration of myoglobin oxidation is reported to be the major cause of colour changes in meat (Genot, 2000). Hierro et al. (2012) observed that PL treatment will induce negative effects on colour of tuna and beef carpaccio only at fluencies higher than $8 \mathrm{~J} \mathrm{~cm}^{-2}$. Keklik et al. (2010) have reported that though PL treatment at fluence of $60.2 \mathrm{~J} \mathrm{~cm}^{-2}$ induced adverse colour changes in vacuum packed chicken breast samples, lower fluences at $2.4 \mathrm{~J} \mathrm{~cm}^{-2}$ and even $24.2 \mathrm{~J} \mathrm{~cm}^{-2}$ did not affect the colour profile. Similarly UV exposure between 2.7 and $5.4 \mathrm{~J} \mathrm{~cm} \mathrm{~cm}^{-2}$ did not produce any undesirable colour changes in chicken breast samples. The results of our studies also indicated that lower fluences that fall within the approved limits of FDA do not induce drastic colour changes in yellowfin tuna steaks.

\section{Changes in sensory evaluation scores}

The results of sensory evaluation of control and PL samples are depicted in Fig. 5. These results showed a significant reduction in the sensory score with respect to storage period for both the samples $(p<0.05)$. The acceptability of the samples was set at a value of 4 and it was found that PL samples did not cross the acceptability limit until the $26^{\text {th }}$ day. In fatty fish, characteristic sensory changes are brought about mainly by degradation of lipids. In the present study, TBA values of the control sample crossed the acceptability limit on the $12^{\text {th }}$ day. From the $12^{\text {th }}$ day, the sensory evaluation scores also showed sudden drop and crossed acceptability limit on $16^{\text {th }}$ day. The results indicated that changes in sensory quality were mainly affected by deterioration in fat quality. The overall evaluation implied that better organoleptic score was attained by PL sample on any day throughout the storage study period and the PL samples achieved a shelf life of 26 days.

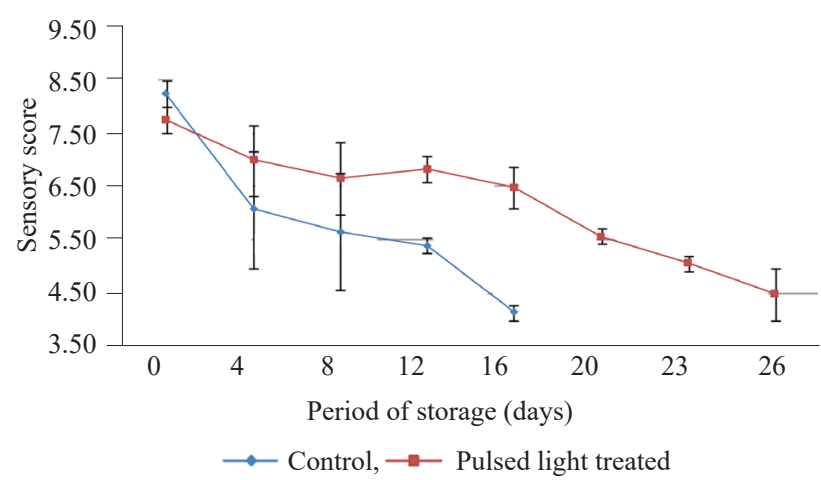

Fig. 5. Changes in sensory scores of control and PL treated yellowfin tuna steaks stored in chilled condition $\left(2 \pm 1^{\circ} \mathrm{C}\right)$ with respect to storage days.

Results of the present study evidence the effectiveness of PL treatment on extension of shelf life of yellowfin tuna steaks through the inactivation of microorganisms. PL is a novel non-thermal processing technology and currently it is relatively the most under-investigated methods. Microbiological and sensory parameters indicated that the PL treated samples were acceptable upto 26 days of storage, whereas the control samples were rejected after 13 days. Though the difference in TPC counts between the control and PL treated samples was $0.3 \log \mathrm{cfu}$, the increase in counts in each sampling interval was very small for PL when compared to that of control. This supports the claim of PL technology in its effectiveness to damage the microbial DNA structure and cell wall (McDonald et al., 2000; Takeshita et al., 2003). Also, the sensory and colour attributes of the PL treated sample remained high upto the $26^{\text {th }}$ day. Thus it can be inferred from the overall 
observations that PL treatment on yellowfin tuna steaks can provide an extension of shelf life for up to 26 days compared to 13 days of control sample.

The present study established the efficacy of PL treatment in microbial inactivation without affecting the sensory attributes of the fish. The results are extremely promising as the shelf life of yellowfin tuna is found to be enhanced in multiples of time periods as compared to conventional methods. Further detailed studies are necessary for characterising the PL efficiency for various food substrates and also for optimising the critical process parameters to achieve target inactivation levels for specific food applications without affecting their sensory quality. Also, there is a need for designing novel technologies for developing pulsed light equipment which are to be compared with other non-thermal and conventional thermal processes in terms of microbial inactivation and preservation efficiency.

\section{Acknowledgments}

Authors acknowledge the financial support received from World Bank funded-National Agricultural Innovation Project, for carrying out this study under the sub project "A Value Chain on Oceanic Tuna Fisheries in Lakshadweep Sea".

\section{References}

Amegovu, A. K., Sserunjogi, M. L., Ogwok, P. and Makokha, V. 2012. Nucleotide degradation products, total volatile basic nitrogen, sensory and microbiological quality of Nile perch (Lates niloticus) fillets under chilled storage. J. Microbiol. Biotechnol. Food Sci., 2(2): 653-666.

AOAC 2002. Official methods of analysis, vol. 1, 17 th edn. Association of Official Analytical Chemists International, Gaithersburg, MD, USA.

APHA 2015. Compendium of methods for the microbiological examination of foods, $5^{\text {th }}$ edn. Yvonne Salfinger and Mary Lou Tortorello (Eds.). American Public Health Association, Washington, D C, USA.

Ashie, I. N. A., Smith, J. P., Simpson, B. K. and Haard, N. F. 1996. Spoilage and shelf-life extension of fresh fish and shellfish, Crit. Rev. Food Sci. Nutr., 36:1-2, 87-121. DOI:10.1080/10408399609527720.

Bang-Yuan Chen, Hsiang-Mei Lung, Binghuei Barry Yang and Chung-Yi Wang 2015. Pulsed light sterilization of packaging materials. Food Pack. Shelf Life., 1-9.

Banks, H., Nickelson, R. and Finne, G. 1980. Shelf life studies on carbon dioxide packaged finfish from Gulf of Mexico. J. Food Sci., 45:157-192. doi.org/10.1111/j.1365-2621. 1980 tb02566.x.

Biji, K. B., Remya Kumari, K. R., Anju, K. A., Suseela Mathew and Ravishankar, C. N. 2016. Quality characteristics of yellow fin tuna (Thunnus albacares) in the fish landing centre at Cochin, India. Fish. Technol., 53: 313-319.
Boselli, E., Caboni, M. F., Rodriguez-Estrada, M. T., Toschi, T. G., Daniel, M. and Lercker, G. 2005. Photoxidation of cholesterol and lipids of turkey meat during storage under commercial retail conditions. Food Chem., 91(4):705-713.

Butz, P. and Tauscher, B. 2002. Emerging technologies: Chemical aspects. Food Res. Int., 35: 279-284. DOI: 10.1016/S09639969(01)00197-1.

Cheigh, C. I., Hwang, H. J. and Chung, M. S. 2013. Intense pulsed light (IPL) and UV-C treatments for inactivating Listeria monocytogenes on solid medium and seafoods. Food Res. Int., 54: 745-752. doi.org/10.1016/j.foodres.2013.08.025.

Cho, S., Endo, Y, Fujimoto, K. and Kaneda, T. 1989. Oxidative deterioration of lipids in salted and dried sardines during storage at 5 ${ }^{\circ}$ C. Nippon Suisan Gakkaishi, 55: 541-544.

Conway, E. J. 1950. Micro-diffusion analysis and volumetric error. Crosby Lockwood and Son Ltd., London, UK.

Dalgaard, P. 2000. Fresh and lightly preserved seafood; shelf-life evaluation of foods, Aspen Publishers, London, UK.

Dunn, J., Ott. T. and Clark, W. 1995. Pulsed-light treatment of food and packaging. Food Technol., 49: 95-98.

FDA 1996. Code of Federal Regulations, 21CFR179.41. Food and Drugs Asministration, Maryland, USA.

Fernandez, M. and Hierro, E. 2016. Microbial inactivation on foods by pulsed light. In: Pataro, G. and Lyng, J. (Eds.), High intensity pulsed light in processing and preservation of foods. Nova Science Publishers, Inc., New York, USA, p. 131-161.

Figueroa-Garcia, J. E., Silva, J. L., Kim, T., Boeger, J., Cover, R. 2002. Use of pulsed-light to treat raw channel catfish fillets. J. Miss. Acad. Sci., 47 (2): 114-120.

Fine, F. and Gervais, P. 2004. Efficiency of pulsed UV light for microbial decontamination of food powders. J. Food Prot., 67: 787-792. DOI:10.4315/0362-028x-67.4.787.

Genot, C. 2000. Freezing and meat quality. Inra Editions, Paris, France (In French).

Gomez-Lopez, V.M., Ragaert, P., Debevere, J.and Devlieghere, F. 2007. Pulsed light for food decontamination: A review. Trends Food Sci. Technol., 18: 464-473 doi.org/10.1016/j. tifs.2007.03.010.

Gram, L. 1995. Bacteriological changes. Paper No. 348. In H. H. Huss (Ed.), Quality and quality changes in fresh fish. FAO Fisheries Technical Paper, Food and Agriculture Organisation, Rome, Italy, p. 51-64.

Gram, L. and Huss, H. H. 1996. Microbiological spoilage of fish and fish products. Int. J. Food Microbiol., 33: 121-137. DOI:10.1016/0168-1605(96)01134-8.

Haghparast, S., Kashiri, H., Shabanpour, B. and Pahlavani, M. H. 2010. Antioxidant properties of sodium acetate, sodium citrate and sodium lactate on lipid oxidation in rainbow trout (Onchorhynchus mykiss) steaks during refrigerated storage $\left(4^{\circ} \mathrm{C}\right)$. Iran. J. Fish. Sci., 9: 73-78. 
Hierro, E., Ganan, M., Barroso, E. and Fernandez, M. 2012. Pulsed light treatment for the inactivation of selected pathogens and the shelf-life extension of beef and tuna carpaccio. Int. J. Food Microbiol., 158: 42-48. DOI: 10.1016/j.ijfoodmicro.2012.06.018.

Huang, Y. W., Lovell, R. T. and Dunham, R. A. 1994. Carcass characteristics of channel and hybrid catfish and quality changes during refrigerated storage. J. Food Sci., 59(1): 64-66. doi.org/10.1111/j.1365-2621.1994.tb06898.x.

Huss, H. H. 1994. Assurance of seafood quality. FAO Fisheries Technical Paper No. 334, Food and Agriculture Organisation, Rome, Italy.

Huss, H. H. 1995. Quality and quality changes in fresh fish FAO Fisheries Technical Paper No. 348. Food and Agriculture Organisation, Rome, Italy, p. 413-430.

ICMSF 1986. Microorganisms in foods 2. Sampling for microbiological analysis: Principles and specific applications, $2^{\text {nd }}$ edn. University of Toronto Press, Buffalo, New York, USA.

Izquier, A., Gomez-Lopez, V. M. 2014. Effects of pulsed light on the organoleptic properties and shelf-life extension of pork and salmon. Food Microbiol., 28: 1170-1174.

Keklik, N. M., Demirci, A. and Puri, V. M. 2010. Decontamination of unpackaged and vacuum-packaged boneless chicken breast with pulsed ultraviolet light. Poult. Sci., 89: 570-581. doi: 10.3382/ps.2008-00476.

Krishnamurthy, K., Tewari, J. C., Irudayaraj, J., and Demirci, A. 2010. Micropscopic and spectroscopic evaluation of inactivation of Staphylococcus aureus by pulsed UV light and infrared heating. Food Bioprocess. Technol., 3: 93-104.

Lakshmanan, P. T. 2000. Fish spoilage and quality assessment. In: Iyer, T. S. G., Kandoran, M. K., Mary Thomas and Mathew P. T. (Eds.), Quality assurance in seafood processing. Society of Fisheries Technologists (India), Kochi, India, p. 26-40.

Leistner, L. 2002. Hurdle technology. In: Juneja, V. K. and Sofos, J. N. (Eds.), Control of food borne microorganisms: Marcel Dekker AG, New York, USA, p. 493-508.

MacGregor, S. J., Rowan, N. J., McIlvaney, L., Anderson, J. G., Fouracre, R. A. and Farish, O. 1998. Light inactivation of food-related pathogenic bacteria using a pulsed power source. Lett. Appl. Microbiol., 27: 67-70. doi.org/10.1046/ j.1472-765X.1998.00399.x.

Manju, S., Jose, L., Gopal, T. S., Ravishankar, C. N. and Lalitha, K.V. 2007. Effects of sodium acetate dip treatment and vacuum-packaging on chemical, microbiological, textural and sensory changes of pearlspot (Etroplus suratensis) during chill storage. Food Chem., 102(1): 27-35.

Mazorra-manzano, M. A., Pacheco-aguilar, R., Díaz-rojas, E. I. and Lugo-sanchez, M. E. 2000. Postmortem changes in black skipjack muscle during storage in ice. J. Food Sci., 65: 774-779.
McDonald, K. F., Curry, R. D., Clevenger, T. E., Unklesbay, K., Eisenstark, A., Golden, J. and Morgan, G. D. 2000. A comparison of pulsed and continuous ultraviolet light sources for the decontamination of surfaces. IEEE Trans Plasma Sci., 28: 1581-1587.

McDonald, R. E. and Hultin, H. O. 1987. Some characteristics of the enzyme lipid peroxidation system in the microsomal fraction of flounder skeletal muscle. J. Food Sci., 52:15-21. doi.org/10.1111/j.1365-2621.1987.tb13964.x.

Meilgaard, M., Civille, G. V. and Carr, B. T. 1999. Sensory evaluation technique, $3^{\text {rd }}$ edn. CRC press, Boca Raton, Florida, USA, $387 \mathrm{pp}$.

Muhammet, B. and Sevim, K. 2007. Storage properties of three types of fried whiting balls at refrigerated temperatures. Turk. J. Fish. Aquat. Sci., 7: 65-70.

Muredzi, P. 2012. Emerging non-thermal food processing technologies. Cambridge Brick House Inc., Lawrence, Massachusetts, USA.

Nicorescu, I., Nguyen, B., Chevalier, S. and Orange. N. 2014. Effect of pulsed light on the organoleptic properties and shelf life extension of pork and salmon. Food control., 44: 138-145. doi.org/10.1016/j.foodcont.2014.03.052.

Nolan, N. L., Bowers, L. A. and Kropf, D. H. 1989. Lipid oxidation and sensory analysis of cooked pork and turkey stored under modified atmospheres. J. Food Sci., 54: 846.

Oms-Oliu, G., Martín-Belloso, O. and Soliva-Fortuny, R. 2010. Pulsed light treatments for food preservation. A review. Food Bioproc. Technol., 3: 13-23. DOI: 10.1007/s11947008-0147-x.

Ortega-Rivas, E. 2012. Pulsed light technology. In: Non-thermal food engineering operations, Food Engineering Series. Springer Science C Business Media, New York, USA, p. 263-273.

Ozer, N. P. and Demirci, A. 2006. Inactivation of Escherichia coli $\mathrm{O} 157$ : $\mathrm{H} 7$ and Listeria monocytogenes inoculated on raw salmon fillets by pulsed UV-light treatment. Int J. Food Sci. Technol., 41: 354-360. doi.org/10.1111/j.13652621.2005.01071.x.

Ozogul, Y., Ozogul, F., Kuley, E., Ozkutuk, A. S., Gokbulut, C. and Kose, S. 2006. Biochemical, sensory and microbiological attributes of wild turbot (Scophthalmus maximus) from the Black Sea, during chilled storage. Food Chem., 99: 752-758.

Palmieri, L. and Cacace, D. 2005. High intensity pulsed light technology: In: Sun, D. W. (Ed.), Emerging technologies for food processing. Elsevier Academic Press, London, UK, p. 279-306.

Pataro, G., Munoz, A., Palgan, I., Noci, F., Ferrari, G. and Lyng, J. G. 2011. Bacterial inactivation in fruit juices using a continuous flow pulsed light (PL) system. Food Res. Int., 44: 1642-1648. doi.org/10.1016/j.foodres.2011.04.048. 
PPT 1999. Pure Pulse Technologies Brochure. PureBright coolPure advanced sterilization, decontamination and preservation technology for the food and food packaging industry. Pure Pulse Technologies Inc., San Dieago, CA, USA. http:/www.packaging2000.compurepulse/purepulse.html.

Ramos-Villarroel, A. Y., Aron-Maftie, N., Martin-Belloso, O. and Soliva-Fortuny, R. 2012. The role of pulsed light spectral distribution in the inactivation of Escherichia coli and Listeria innocua on fresh-cut mushroom. Food Control., 24: 206-213. DOI10.1016/j.foodcont.2011.09.029.

Rodriguez-Turienzo, L., Cobos, A. and Diaz, O. 2013. Effects of microbial transglutaminase added edible coatings based on heated or ultrasound treated proteins in physical and chemical parameter of frozen Atlantic salmon (Salmo salar). J. Food Eng., 119: 433-438. DOI: 10.1016/j.jfoodeng. 2013.06.015.

Rowan, N. J., MacGregor, S. J., Anderson, J. G., Fouracre, R. A., Mcllvaney, L. and Farish, O. 1999. Pulsed-light inactivation of food-related microorganisms. J. Appl. Environ. Microbiol., 65: 1312-1315.

Salih, A. M., Smith, D. M. and Price, J. R. 1987. Modified extraction of 2-thiobarbituric acid method for measuring lipid oxidation in poultry. Poult. Sci., 66: 1483-1488. DOI:10.3382/ps.0661483.

Shah, A. J. 1991. Extrusion cooking of corn grits. Ph. D Thesis. School of Food and Fisheries Studies, Humberside Polytechnic, UK.

Sofos, J. N. 2005. Improving the safety of fresh meat. CRC/ Woodhead Publishing Ltd., Cambridge, UK.

Takeshita, K., Shibato, J., Sameshima, T., Fukunaga, S., Isobe, S. and Arihara, K. 2003. Damage of yeast cells induced by pulsed light irradiation. Int. J. Food Microbiol., 85: 151-158. DOI:10.1016/s0168-1605(02)00509-3.
Tarladgis, B. G., Watts, B. M., Younathan, M. T. and Dugan Jr, L. 1960. A distillation method for the quantitative determination of malonaldehyde in rancid foods. J. Am. Oil Chem. Soc., 37(1): 44-48.

Tatiana, N. K., Larry, J. F., Carmen, I. M. 2009. Ultraviolet light in food technology: Principles and application. Taylor and Francis Group, USA.

Turtoi, M. and Nicolau, A. 2007. Intense light pulse treatment as alternative method for mould spores destruction on paper-polyethylene packaging material. J. Food Eng., 83: 47-53. DOI: 10.1016/j.jfoodeng.2006.11.017.

Vanderroost, M., Ragaert, P., Devlieghere, F. and De Meulenaer, B. 2014. Intelligent food packaging: The next generation. Trend. Food Sci. Technol., 39: 4762. DOI: 10.1016/j. tifs.2014.06.009.

Viji, P., Tanuja, S., George Ninan, Zynudheen, A. A. and Lalitha, K. V. 2014. Quality characteristics and shelf life of sutchi cat fish (Pangasianodon hypophthalmus) steaks during refrigerated storage. Int. J. Agri. Food Sci. Technol., 5(2): 105-116.

Wang, T., MacGregor, S. J., Anderson, J. G. and Woolsey, G. A. 2005. Pulsed ultraviolet inactivation spectrum of Escherichia coli. Water Res., 39: 2921-2925. doi:10.1016/j.watres.2005.04.067.

Wekhof, A. 2000. Disinfection with flash lamps. PDA STP Pharma Sciences, 54: 264-276.

Yusuf, A. M., Sharif, M. I., Ripon, K. A. and Faruque, O. 2010. Post-mortem variation in total volatile base nitrogen and trimethylamine nitrogen between Galda (Macrobrachium rosenbergii) and Bagda (Penaeus monodon). Univ. J. Zool. Rajshahi Univ., 28: 7-10. 